\title{
Quantifying photosynthetic rates of microphytobenthos using the triple isotope composition of dissolved oxygen
}

\author{
Rachel H. R. Stanley* and Evan M. Howard \\ Department of Marine Chemistry and Geochemistry, Woods Hole Oceanographic Institution, 360 Woods Hole Road, \\ Woods Hole, MA 02543 USA
}

\begin{abstract}
Microphytobenthos are important mediators of nutrient and carbon fluxes in coastal environments. However, quantifying production rates by microphytobenthos is difficult, and existing methods necessitate perhaps erroneous assumptions that dark respiration equals light respiration. Here we present a new method for quantifying photosynthetic rates of microphytobenthos, i.e., gross primary production, by using the triple isotope composition of dissolved oxygen in benthic flux chambers. Because the triple oxygen isotope signature is sensitive to photosynthesis, but not to respiration, this method allows quantification of gross photosynthetic oxygen fluxes by microphytobenthos without assumptions about respiration. We present results from field experiments in Waquoit Bay, Massachusetts, that illustrate the method.
\end{abstract}

Coastal environments are among the most biogeochemically important globally and are responsible for large $\mathrm{CO}_{2}$ fluxes despite their relatively small area (Borges et al. 2005; Cai 2011; Cai et al. 2006; Chen and Borges 2009). Biogeochemical cycling of carbon and nutrients is intense in estuaries (e.g., Hopkinson and Smith 2005). Humans have heavily impacted coastal zones, and many estuaries show signs of eutrophication (Bricker et al. 2007; Cloern 2001; de Jonge et al. 2002; Nixon 1995) with low water quality, seasonal harmful algal blooms (Paerl 1988), hypoxia (Diaz 2001; Diaz and Rosenberg 1995; Kemp et al. 2009; Rabalais et al. 1996; Turner and Rabalais 1994; Vaquer-Sunyer and Duarte 2008), and fish kills (Thronson and Quigg 2008). Microphytobenthos (MPB), i.e., unicellular benthic photosynthesizers such as diatoms and cyanobacteria, are important mediators of nutrient and car-

*Corresponding author: E-mail: rstanley@whoi.edu

\section{Acknowledgments}

We are grateful to MaryKay Fox and Chris Weidman at the Waquoit Bay National Estuarine Reserve for their support of the fieldwork, Paul Henderson and Meagan Gonneea for assistance with YSIs and flux chambers, Zoe Sandwith for help with triple oxygen isotope analysis, and Amanda Spivak for useful discussions. We thank Matthew Charette for the use of his benthic flux chambers. This work has benefited from the helpful comments of two anonymous reviewers. We gratefully acknowledge funding for this work by the Coastal Ocean Institute of Woods Hole Oceanographic Institution and the National Science Foundation (OCE-82964400). EH was supported by a National Defense Science and Engineering Graduate Fellowship award.

DOI 10.4319/lom.2013.11.360 bon fluxes in these shallow environments (Eyre and Ferguson 2002, 2005; McGlathery et al. 2001; McGlathery et al. 2004; Risgaard-Petersen 2003; Rysgaard et al. 1995; Sundbäck et al. 1991). These producers may account for greater than $50 \%$ of gross primary productivity, i.e., the total photosynthetic flux, in estuaries (Underwood and Kromkamp 1999). Microphytobenthos have been implicated as a major, and in some cases dominant, controlling factor in estuarine nitrogen cycling (Engelsen et al. 2008; Risgaard-Petersen 2003; Tyler et al. 2003). Because of their role in moving nitrogen from the overlying water column into the sediments, it is hypothesized that MPB act to buffer estuaries from the effects of eutrophication (McGlathery et al. 2004; Meyercordt and Meyer-Reil 1999). Increased nutrient loading increases benthic algal biomass (e.g., Cook et al. 2007) and likely stimulates algal production. However, the magnitude of nutrient effects on MPB production rates is rarely measured, and it is possible that the change in production rates may not scale linearly with the change in algal biomass.

A major cause for the uncertainty in how MPB impact and are impacted by eutrophication is the difficulty in measuring production rates in the sediments. Investigators have used radiocarbon slurry injections and incubations of extracted sediment cores to estimate carbon uptake (MacIntyre et al. 1996). However these methods destroy in situ chemical and biological gradients (Cibic et al. 2008). Furthermore, there has been some debate as to whether radiocarbon-based productivity estimates are actually measuring gross or net productivity or something in between (e.g., Dring and Jewson 1982). Oxygen fluxes from incubations of cores in light and dark conditions in labo- 
ratories (Hopkinson et al. 1999; Risgaard-Petersen 2003; Sundbäck et al. 1991), in benthic flux chambers (Cebrian et al. 2008; Jahnke et al. 2000; Jahnke et al. 2008), or from eddy correlation technique (Berg et al. 2003; Glud et al. 2010; Lorrai et al. 2010; McGinnis et al. 2008) are also used to estimate gross and net productivity. However these approaches require the assumption that light and dark respiration are similar, when in fact MPB light respiration appears to be greater than dark respiration by a factor of 1.5 to 2.5 (Epping and Jorgensen 1996; Fenchel and Glud 2000). Often researchers do not measure production at all and instead measure algal biomass using sediment chlorophyll and assume that production scales with biomass. However, the relationship between chlorophyll content and productivity depends on species-dependent physiology and physical factors such as light attenuation and nutrient loading (Cloern et al. 1995), and thus is highly site specific. Additionally, carbon to chlorophyll ratios can vary by almost an order of magnitude (Flynn 2003).

In this article, we describe a new method that we have developed for quantifying MPB photosynthesis based on measurements of triple oxygen isotopes (TOI) — simultaneous measurements of ${ }^{16} \mathrm{O},{ }^{17} \mathrm{O}$, and ${ }^{18} \mathrm{O}$ - in benthic flux chambers. The TOI method quantifies Gross Oxygen Production (GOP), which is defined as the photosynthetic production of oxygen by splitting of the water molecule inside photosystem II. GOP will be greater than gross primary production by approximately $15 \%$ to $25 \%$ because of reactions such as the Mehler reaction and photorespiration that result in production of $\mathrm{O}_{2}$ without concomitant change in carbon (Bender et al. 1999; Halsey et al. 2010; Laws et al. 2000). The TOI method addresses two of the problems associated with commonly used current methods for quantifying benthic photosynthesis. First, TOI directly measure photosynthetic activity, not just a proxy for photosynthesis as chlorophyll does. Second and perhaps most importantly, the TOI signature is not affected by respiration, and therefore there is no need to make any assumptions about light versus dark respiration.

The triple isotope composition of dissolved oxygen has been used successfully in the open ocean for more than a decade to quantify rates of gross photosynthetic oxygen production (Hendricks et al. 2004; Hendricks et al. 2005; Luz and Barkan 2000; Luz et al. 1999; Reuer et al. 2007; Stanley et al. 2010). The TOI approach rests on the observation that photochemical reactions in the stratosphere fractionate oxygen isotopes in a mass independent way (Lammerzahl et al. 2002; Thiemens et al. 1995). In contrast, on the earth's surface, there is mass dependent fractionation with ${ }^{18} \mathrm{O}$ being fractionated twice as much as ${ }^{17} \mathrm{O}$. This results in oxygen in the stratosphere having a distinct ratio of ${ }^{16} \mathrm{O},{ }^{17} \mathrm{O}$ and ${ }^{18} \mathrm{O}$. This unique isotopic signature can be quantified by ${ }^{17} \Delta$ where

$$
{ }^{17} \Delta=\left[\ln \left(\frac{\partial^{17} O}{1000}+1\right)-\gamma_{R} \ln \left(\frac{\partial^{18} O}{1000}+1\right)\right] \times 10^{6}
$$

where $\delta^{17} \mathrm{O}$ and $\delta^{18} \mathrm{O}$ reflect standard isotopic notation $\left(\delta^{\mathrm{x}} \mathrm{O}=\right.$ $\left.\left[\left({ }^{\mathrm{x}} \mathrm{O} /{ }^{16} \mathrm{O}\right)_{\text {smpl }} /\left({ }^{\mathrm{x}} \mathrm{O} /{ }^{16} \mathrm{O}\right)_{\text {std }}-1\right] \times 1000\right)$ and $\gamma_{\mathrm{R}^{\prime}}$, which equals 0.5179 , is the value characterizing the isotopic fractionation associated with dark respiration in a steady-state system (Angert et al. 2003; Luz and Barkan 2005). ${ }^{17} \Delta$ therefore is a measure of the degree of mass independent fractionation. Some of this stratospheric $\mathrm{O}_{2}$ is mixed into the troposphere, giving air a ${ }^{17} \Delta=0$, and ultimately into the surface water of the ocean, estuaries, etc. (Fig. 1a), where due to equilibration processes it has a ${ }^{17} \Delta=8$ to 16 (Luz and Barkan 2009; Reuer et al. 2007; Stanley et al. 2010). In contrast, phytoplankton produce $\mathrm{O}_{2}$ from the oxygen in the water molecule with massdependent fractionation and thus $\mathrm{O}_{2}$ from phytoplankton has the mass-dependent value of ${ }^{17} \Delta \approx 249$ (Luz and Barkan 2000). Thus the triple isotope composition of the dissolved oxygen in water serves as a "made-in tag" - it allows one to quantify what percentage of the oxygen was made by photosynthesis (reflected by a higher ${ }^{17} \Delta$ ) and what percentage was mixed in from air-sea gas exchange (reflected by a lower ${ }^{17} \Delta$ ). Geochemically, this is analogous to a two-end member mixing model with photosynthetic $\mathrm{O}_{2}$ at one end and atmospheric $\mathrm{O}_{2}$ at the other (Fig. 1b). Respiration is a process that removes oxygen in a mass-dependent way and thus does not affect ${ }^{17} \Delta$ (Luz and Barkan 2000, 2009; Luz et al. 1999). Therefore, the TOI technique quantifies photosynthesis only and allows one to calculate GOP without necessitating any assumptions about light or dark respiration.

\section{Materials and procedures}

\section{Benthic flux chambers}

In this method, samples are collected for TOI from benthic flux chambers at regular intervals during a dawn-to-dusk incubation. Thus, the first step is to deploy two flux chambers. One chamber is a stirred acrylic benthic flux chamber of the design of Rao and Charette (2011), which is inserted $11 \mathrm{~cm}$ into the sediment in the desired field location (estuary, lagoon, etc.) at a water depth such that the chamber will still be submerged at low tide and yet will be accessible at high tide. This chamber is referred to as the "light" chamber (Fig. 2). In order to not include any floating macroalgae or grazers in the chamber, a screen (mesh size $=0.5 \mathrm{~mm}$ ) is placed on the open side of the chamber until the chamber is sunk into the sediment (i.e., screen is in place while chamber is being carried to the exact location and water is flowing in). The flux chamber has an inner diameter of $20 \mathrm{~cm}$ and an overall height of $30 \mathrm{~cm}$. A second flux chamber, also made of acrylic, has an inner diameter of $20 \mathrm{~cm}$ and a height of 19 $\mathrm{cm}$, and is sealed on both ends. This chamber is placed so that it rests on the sediment-because the chamber is sealed, the water inside does not contact the sediment and thus we refer to it as the "water" chamber. The water chamber has the same volume as the overlying water of the light chamber and is used to correct the measured rates of production for production occurring in the water column. It rests on the sediment so that it is exposed to the same light field as the light 

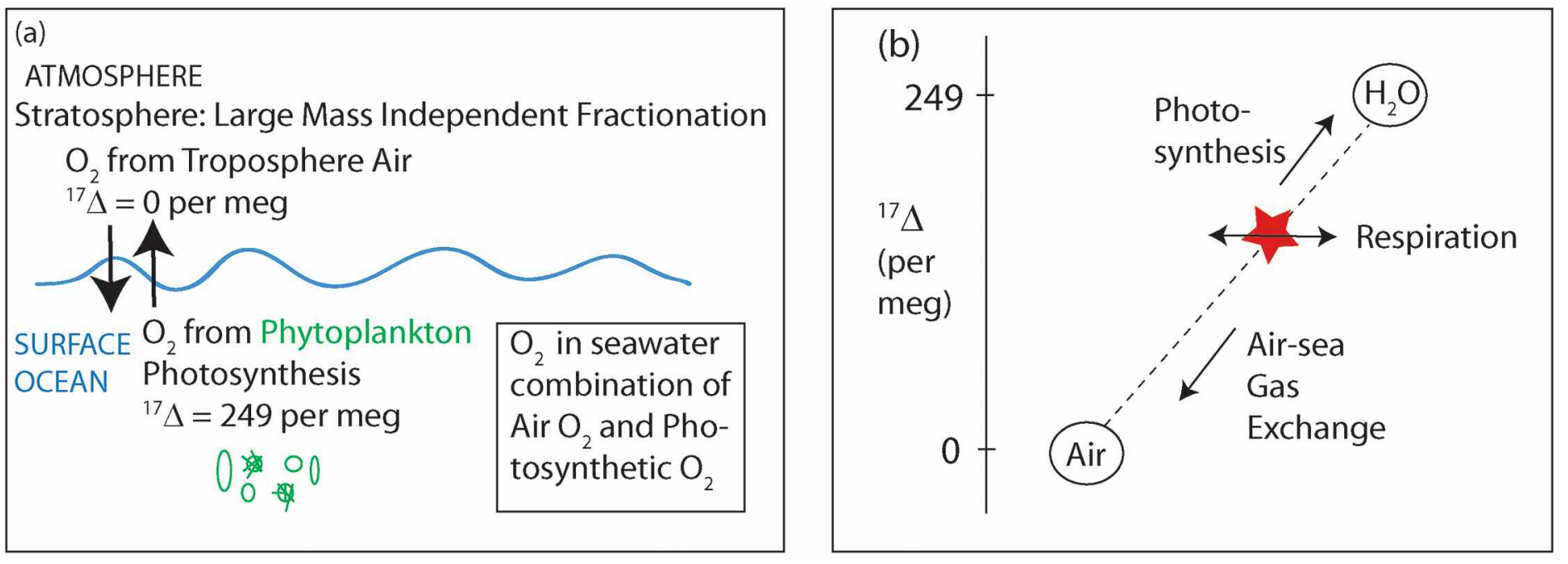

Fig. 1. Cartoons illustrating the triple oxygen isotope (TOI) approach. (a) Mass independent reactions in the stratosphere result in air having a different TOI signature, as evidenced by ${ }^{17} \Delta$, than oxygen produced by photosynthesis. Dissolved oxygen in the water is a combination of both end-members and the proportion of oxygen from air versus oxygen from photosynthesis can be calculated from the ${ }^{17} \Delta$. (b) This is analogous to a geochemical two end-member mixing model with oxygen from air as one end-member and oxygen produced by photosynthesis from the water molecules as the other. Respiration does not affect the ${ }^{17} \Delta$.

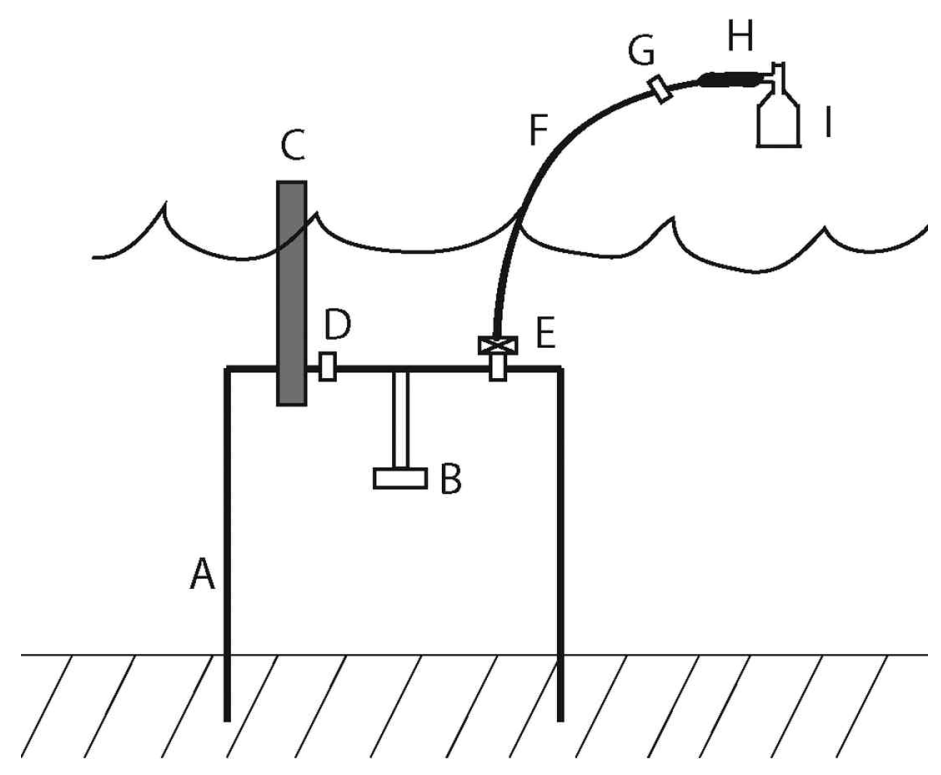

Fig. 2. Schematic of benthic flux chamber and sampling set-up (not drawn to scale). The chamber $(A)$ is inserted $\sim 10 \mathrm{~cm}$ into the sediment. It is stirred (B) and has a YSI (C) for recording oxygen concentration, temperature, and salinity. A replacement port (D) allows water from the surrounding water column to replace the water drawn by sampling from a valved port (E). Samples are drawn through $1 / 4$-inch tygon tubing (F), which can be clamped $(G)$ and is connected to more flexible 1/4-inch silicone tubing $(\mathrm{H})$, and into an evacuated, poisoned, sample bottle (I).

chamber. Both chambers are stirred continuously, using acrylic rods, at rates of 6 RPM. A YSI multiprobe sonde (model 600xlm) is screwed into the flux chamber lid at the start of each chamber incubation and records the temperature, salinity, and oxygen concentration in the chamber. The chambers are strapped using cargo straps to metal anchors screwed into the sediment to prevent the chambers from being moved by the ocean currents. The chambers are deployed near dawn and removed at dusk to quantify production for the entire day. If desired, one could deploy the chamber for a shorter period.

Sampling from the flux chambers

Samples for TOI analysis are withdrawn from both the benthic and the water column chambers at the start of the incubation period (i.e., as soon as the chambers are deployed) and at roughly 2 -h time increments until the incubation is finished (i.e., chambers are removed). Samples are drawn through 1/4-inch tygon tubing through a valved port in the chamber lid (Fig. 2) in the benthic and water column chambers. Just before removing the sample, a cap is removed from a different port $(2.8 \mathrm{~mm}$ ID) in the chamber lid so that water from the surrounding ocean replaces the water withdrawn through the tubing. The replacement port is on the opposite side of the sampling tubing so that the replacement water is not entrained in the sample. This replacement water is accounted for in the corrections (see Appendix A). Samples are collected in custom-made evacuated glass sample bottles (Emerson et al. 1999) that have been poisoned previously with $100 \mu \mathrm{L}$ saturated mercuric chloride solution. It is imperative not to get air into the sample bottles while collecting the sample. Thus, a hand pump is used to draw water from the flux chamber into the sampling tube, and the tube is clamped off. The clamp is then loosened as a syringe is used to withdraw from the tubing a volume of water $(60 \mathrm{~mL}$ in our case) equal to the volume in the tube since the tubing initially has surrounding seawater. That water is disposed of. Then the syringe is used to withdraw an additional $30 \mathrm{~mL}$ water from the tub- 
ing. A piece of silicon tubing (ID $=1 / 4$-inch) is attached to the tygon tubing after the clamp. The $30 \mathrm{~mL}$ water from the syringe is used to fill this silicon tubing and the neck of the sample bottle. Quickly, the outer tubing is put onto the sample bottle neck without any air being entrained. A visual check for bubbles is performed. If bubble-free, then the clamp on the tubing is opened, the $9 \mathrm{~mm}$ glass Louwers-Hapert valve on the sample bottle is opened, and water fills the sample bottle until the bottle is half full $(300 \mathrm{~mL})$. The Louwers-Hapert valve is closed, and tubing is clamped shut. If a duplicate is being taken, water from the syringe is used to fill the neck of the duplicate sample bottle. There is no need to refill the tubing. Once all samples have been taken from a chamber, the valve on the tubing is closed, the tubing is removed, and the plug on the replacement water port is put in place. The necks of the sample bottles are filled with seawater to slow diffusion of gases across the o-rings in the Louwers-Hapert valves (Hamme and Emerson 2004).

Additionally, at every time point, samples are taken in the surrounding water column by submerging an evacuated, poisoned sample bottle completely in the ocean (near the flux chambers but not attached to them), and opening the Louwers-Hapert valve until the sample bottle is approximately half full. The valve is then closed, and the sample neck filled with seawater.

\section{Isotopic analysis of samples}

Samples are returned to the laboratory and analyzed for triple oxygen isotopes on an isotope ratio mass spectrometer following the method of Barkan and Luz (2003). In brief, the bottles are shaken for $6 \mathrm{~h}$ to equilibrate the water with the headspace. The bottles are inverted, and water is then drained out of the sample bottles, while the headspace is carefully preserved. The sample bottles are connected through ultratorr compression fittings to an automated, stainless steel processing line. The necks in the sample bottles are pumped with a mechanical pump and then a turbomolecular pump for 10 and $20 \mathrm{~min}$, respectively. Pneumatic valves are closed to isolate the bottles from the pumps and then, one at a time, a sample is opened. The gas is expanded through a trap at $-70^{\circ} \mathrm{C}$ to remove water and then collected onto a U-trap filled with molsieve $5 \mathrm{~A}$ submerged in liquid $\mathrm{N}_{2}$. The molseive trap is heated, and the gas is passed through a $3 \mathrm{~m}$ molseive $5 \mathrm{~A}$ GC column held at $-3^{\circ} \mathrm{C}$. The $\mathrm{O}_{2}$ and $\mathrm{Ar}$ are eluted from the column first ( $\mathrm{t}=5 \mathrm{~min})$ and are collected in a U-trap filled with molsieve 5a and submerged in liquid $\mathrm{N}_{2} . \mathrm{N}_{2}$ is eluted from the column at $>16 \mathrm{~min}$ and is not collected. The molseive $\mathrm{U}$ trap with $\mathrm{O}_{2}$ and $\mathrm{Ar}$ is warmed, and the gas is transferred to a cryogenic trap at $10 \mathrm{~K}$ (Lott 2001). After all the gas is transferred, the trap is isolated and warmed to room temperature. The gas is then released into the isotope ratio mass spectrometer and run against a reference gas, which is mixed to have a similar $\mathrm{O}_{2} / \mathrm{Ar}$ ratio as that of seawater. Once a day, the reference gas is run against an aliquot of an air standard taken outside in Woods Hole, Mas- sachusetts. Also every day, a sample of water that has been equilibrated with the atmosphere is run to check that the processing line is running smoothly. Approximately 10 samples can be run in a 24 -h period.

\section{Calculation of GOP}

In the open ocean, rates of GOP were traditionally calculated from ${ }^{17} \Delta$, directly assuming a steady state balance between photosynthesis and air-sea gas exchange (Luz and Barkan 2000). Recently, revised equations that directly use the isotopic ratios of ${ }^{18} \mathrm{O} /{ }^{16} \mathrm{O}$ and ${ }^{17} \mathrm{O} /{ }^{16} \mathrm{O}$ (i.e., $\delta^{18} \mathrm{O}$ and $\delta^{17} \mathrm{O}$ ) have been shown to be more accurate (Kaiser 2011; Prokopenko et al. 2011). Here rates of GOP are calculated from the isotopic ratios $\delta^{18} \mathrm{O}$ and $\delta^{17} \mathrm{O}$. The GOP equation in the absence of gas exchange or advection (Eq. 42 in Kaiser [2011]), reproduced here, is used as a starting point:

$$
G O P=\left[O_{2}\right] \frac{\left(\frac{1}{1+\delta^{17} o}\right)\left(\frac{\partial \delta^{17} o}{\partial t}\right)-\gamma_{R}\left(\frac{1}{1+\delta^{18} o}\right)\left(\frac{\partial \delta^{18} o}{\partial t}\right)}{\left(\frac{\delta^{17} O_{P}-\delta^{17} o}{1+\delta^{17} O}\right)-\gamma_{R}\left(\frac{\delta^{18} O_{P}-\delta^{18} O}{1+\delta^{18} O}\right)}
$$

where GOP equals the volumetric production rate, $\left[\mathrm{O}_{2}\right]$ is the concentration of $\mathrm{O}_{2}$, and $\delta^{x} \mathrm{O}_{\mathrm{p}}$ is the ${ }^{\mathrm{x}} \mathrm{O}$ isotopic value of oxygen produced by photosynthesis. The GOP at a given time $t_{n}$ in the flux chambers can be computed by discretizing Eq. 2:

$$
G O P=\left[O_{2}\right]_{\text {avg }} \frac{\left(\frac{1}{1+\delta^{17} o_{n}}\right)\left(\frac{\delta^{17} o_{n}-\delta^{17} o_{n-1}}{t_{n}-t_{n-1}}\right)-\gamma_{R}\left(\frac{1}{1+\delta^{18} o_{n}}\right)\left(\frac{\delta^{18} o_{n}-\delta^{18} o_{n-1}}{t_{n}-t_{n-1}}\right)}{\left(\frac{\delta^{17} o_{P^{-} \delta^{17} o_{\text {avg }}}}{1+\delta^{17} o_{\text {avg }}}\right)-\gamma_{R}\left(\frac{\delta^{18} o_{P}-\delta^{18} o_{\text {avg }}}{1+\delta^{18} o_{\text {avg }}}\right)}
$$

where $\delta^{\mathrm{x}} \mathrm{O}_{n}$ and $\delta^{\mathrm{x}} \mathrm{O}_{n-1}$ are the measured and replacement-volume corrected isotopic values of the samples withdrawn from the flux chambers at times $n$ and $n-1$, respectively (see below for explanation of replacement volume correction), $\left[\mathrm{O}_{2}\right]_{\text {avg }}$ is the average $\mathrm{O}_{2}$ concentration in the chambers over the interval between the $n$ and $n-1$ time points, and $\delta^{\mathrm{x}} \mathrm{O}_{\text {avg }}$ is the average of the volume-corrected isotopic values of the samples withdrawn at the $n$ and $n-1$ time points. Practical considerations make using averages, rather than instantaneous, values of $\left[\mathrm{O}_{2}\right]$ and $\delta^{x} \mathrm{O}$ necessary. If the interval of discretization is small enough, it should not matter if $\left[\mathrm{O}_{2}\right]_{\mathrm{avg}}\left[\mathrm{O}_{2}\right]_{n^{\prime}}$ or $\left[\mathrm{O}_{2}\right]_{n-1}$ as well as $\delta^{\mathrm{x}} \mathrm{O}_{a v g^{\prime}} \delta^{\mathrm{x}} \mathrm{O}_{n^{\prime}}$ or $\delta^{\mathrm{x}} \mathrm{O}_{n-1}$ are used. In practice, the interval of discretization is not quite small enough and thus there is a difference in GOP of approximately $10 \%$ based on whether one uses average value of $\delta^{x} \mathrm{O}$ in Eq. 3 or isotopic values at time point $n$.

The replacement-volume correction is necessary to correct the measured value at time $n-1$ for water mixed in from the surrounding water column during sampling. We assume that water replacing the current sample has not yet mixed and changed the isotopic value because of the spatial separation in ports. Thus the replacement-volume correction is only made to $\delta^{\mathrm{x}} \mathrm{O}_{n-1}$. The correction is made according to: 


$$
\begin{gathered}
\delta^{x} O_{n-1}= \\
\frac{\left(\delta^{x} O_{\text {measured, }}{ }_{n-1}\right)\left(V_{\text {total }}-V_{\text {exchanged }, n-1}\right)+\left(\delta^{x} O_{\text {water, }} n-1\right)\left(V_{\text {exchanged } n-1}\right)}{V_{\text {total }}}
\end{gathered}
$$

where $\delta^{\mathrm{x}} \mathrm{O}_{\text {measured }, n-1}$ is the measured isotopic value of the sample from the chamber, $\delta^{x} \mathrm{O}_{\text {water }}$ is the isotopic value of $\mathrm{O}_{2}$ dissolved in the surrounding water column (i.e., not in any chamber), $V_{\text {total }}$ is the total volume of the flux chamber, and $V_{\text {exchanged, } n-1}$ is the amount of water withdrawn for the $n-1$ sample and includes volume of sample itself plus the volume of water in the tubing and water taken with the syringe. $V_{e x-}$ changed, $n-1$ typically ranged from $350 \mathrm{~mL}$ to $700 \mathrm{~mL}$ depending on whether one or two samples were taken.

To assess the required frequency of sampling, we also calculated GOP based on only the initial ( $i$ ) and final $(f)$ samples. We did this by using Eq. 3 with $n$ values appropriate for the final sample and $n-1$ values appropriate for the initial sample. In this case, however, the correction for mixing of replacement water is more complicated because of intermediate sampling and is calculated according to:

$\delta^{x} O_{i}=$
$\frac{\left(\delta^{x} O_{\text {measured, } i}\right)\left(V_{\text {total }}-\sum_{n=i}^{f-1}\left[V_{\text {exchanged, } n-1}\right]\right)+\sum_{n=i}^{f-1}\left[\left(\delta^{x} O_{\text {water, }, n}\right)\left(V_{\text {exchanged }, n-1}\right)\right]}{V_{\text {total }}}$

In Eq. 3, we use $\gamma_{\mathrm{R}}$, the fractionation factor associated with respiration, to be 0.5179 (Luz and Barkan 2005). This fractionation factor has never been measured for MPB but given the extremely small variation seen for a wide range of organisms and conditions (Luz and Barkan 2005), differences in $\gamma_{R}$ are expected to be negligible. In contrast, $\delta^{\mathrm{x}} \mathrm{O}_{\mathrm{p}}$ does vary between different types of algae (Eisenstadt et al. 2010; Helman et al. 2005; Luz and Barkan 2011) but has not been measured for $\mathrm{MPB}$. Currently, one can use $\delta^{x} \mathrm{O}_{\mathrm{p}}$ measured for pelagic types but future work should include measuring $\delta^{\mathrm{x}} \mathrm{O}_{\mathrm{P}}$ for benthic strains.

The rates of GOP are calculated in each chamber (i.e., light or water) according to Eqs. 3-5. The rate of GOP attributable specifically to MPB is then calculated as the difference between the light and water chambers:

$$
G O P_{\text {benthic }}=G O P_{\text {light }}-G O P_{\text {water }}
$$

where $G O P_{\text {light }}$ is the rate of GOP calculated for the light chamber and $G O P_{\text {water }}$ is the rate of GOP calculated for the water chamber. Additionally, the proportion of benthic gross primary production, $\%_{\text {benthic, }}$ can be calculated as

$$
\%_{\text {benthic }}=\frac{\text { GOP }_{\text {benthic }}}{G O P_{\text {light }}} \times 100 \%
$$

and the proportion of pelagic gross oxygen production, $\%_{\text {water }}$, as

$$
\%_{\text {water }}=\frac{G O P_{\text {water }}}{G O P_{\text {light }}} \times 100 \%
$$

\section{Assessment}

\section{Site description}

We applied this method at Waquoit Bay in Cape Cod, Massachusetts, USA. Waquoit Bay is a semi-enclosed estuary with a mean water depth of $1 \mathrm{~m}$. The bay is tidally flushed with water from Vineyard Sound in the South. The sediment is relatively homogenous and permeable. Groundwater is the major source of freshwater to the bay (Charette et al. 2001; Valiela et al. 1990). In this study, the benthic flux chambers were intentionally placed in regions where the least groundwater discharge occurs and the lack of salinity change in the chamber over the course of the day confirmed that groundwater fluxes were negligible. Microphytobenthic chlorophyll $a$ has not been measured directly at the head of the bay (where we sampled) but has been measured in other parts of the Waquoit Bay estuarine system (Lever and Valiela 2005). The concentrations range from 50 to $90 \mathrm{mg} \mathrm{m}^{-2}$ in the pristine Sage Lot pond area to 90 to $120 \mathrm{mg} \mathrm{m}^{-2}$ in the humanimpacted Childs River area and in both areas follows a seasonal cycle with Chl $a$ peaking in July and August (Lever and Valiela 2005). The head of the bay has a nutrient loading in between Sage Lot Pond and Childs River.

\section{Application of method}

To test this method, we deployed light and water column flux chambers at the head of Waquoit Bay on 2 days in October 2011, according to the protocols described in "Materials and Methods" above. The ${ }^{17} \Delta$ in the light and water column chambers increased over the course of the deployment on both days (only 1 day shown, Fig. 3a) signifying that gross production was occurring. ${ }^{17} \Delta$ increased more in the light chamber than in the water chamber, illustrating that MPB were present and photosynthesizing. We calculated rates of GOP from the isotopic values at each time point using Eq. 3 and 4 (Fig. 3b, Table 1) and, as expected, the rate of GOP is higher in the light chamber than the water chamber. The difference between the GOP rates in the light chamber and water chamber is equal to the GOP due to MPB (Fig. 3c). By integrating the GOP rates throughout the day (area under the GOP curve in Fig. 1c), we calculated cumulative rates of MPB GOP to be $20 \pm 2 \mathrm{mmol} \mathrm{O}_{2} \mathrm{~m}^{-2}$ on 7 Oct for the $9.5 \mathrm{~h}$ incubation and $18 \pm 2 \mathrm{mmol} \mathrm{O}_{2} \mathrm{~m}^{-2}$ on 10 Oct for the 10 -h incubation. Using a photosynthetic quotient of 1 and assuming that the incubations covered the entire photosynthetic period, these rates are equivalent to 212 to $236 \mathrm{mg} \mathrm{C} \mathrm{m}^{-2} \mathrm{~d}^{-1}$. This is in the range of the rates of 6 to $450 \mathrm{mg} \mathrm{C} \mathrm{m}^{-2} \mathrm{~d}^{-1}$ by MPB that have been observed in Naragansett Bay (Lake and Brush 2011), and the rates of 50 to $750 \mathrm{mg} \mathrm{C} \mathrm{m}^{-2} \mathrm{~d}^{-1}$ by MPB that have been measured on the Georgia continental shelf (Jahnke et al. 2000; 

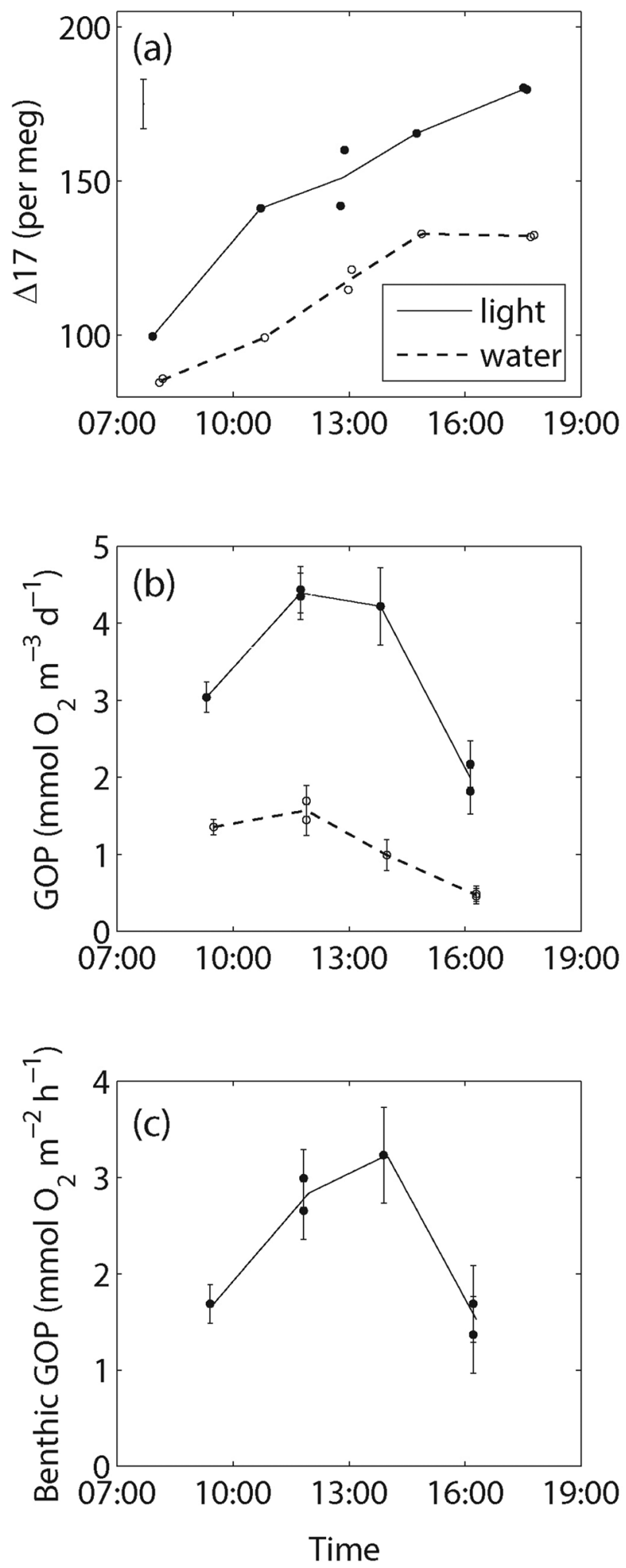

Fig. 3. (a) The triple isotopic signature, ${ }^{17} \Delta$, in the light (solid) and water (dash) chambers on 7 Oct 2011. The error bar in top left corner reflects $1 \sigma$ measurement uncertainty. (b) Rates of GOP in the two chambers. (c) Rate of benthic GOP, i.e., GOP attributable to MPB production. Error bars on all GOP rates represent $1 \sigma$ uncertainty from Monte Carlo analysis.
Table 1. GOP in the light and water column chambers as well as estimated benthic GOP. The proportion of benthic and pelagic GOP to total production is listed as well. Calculations performed using all time-points ("time-series") and only using initial and final data points ("initial to final").

\begin{tabular}{lcccc}
\hline Type & \multicolumn{4}{c}{ GOP $\left(\mathrm{mmol} \mathrm{O}_{2} \mathbf{~ m}^{-2}, \%\right.$ of total) } \\
\hline \multicolumn{5}{c}{ Time-series } \\
\hline 7-Oct-2011 & & & & Initial to final \\
Light & $29.3 \pm 1.7$ & & $26.8 \pm 1.2$ & \\
Water & $9.5 \pm 0.7$ & $32 \pm 2 \%$ & $8.9 \pm 0.4$ & $33 \pm 2 \%$ \\
Benthic & $19.7 \pm 1.6$ & $67 \pm 5 \%$ & $17.9 \pm 1.0$ & $67 \pm 4 \%$ \\
10-Oct-2011 & & & & \\
Light & $25.0 \pm 1.7$ & & $22.3 \pm 1.1$ & \\
Water & $7.3 \pm 0.7$ & $29 \pm 3 \%$ & $6.7 \pm 0.4$ & $30 \pm 2 \%$ \\
Benthic & $17.7 \pm 1.7$ & $71 \pm 7 \%$ & $15.5 \pm 1.0$ & $70 \pm 4 \%$ \\
15-Oct-2011 & & & & \\
Light & $26.8 \pm 1.7$ & & $23.6 \pm 0.8$ & \\
Dark & $0.5 \pm 1.0$ & & $0.1 \pm 0.5$ & \\
\hline
\end{tabular}

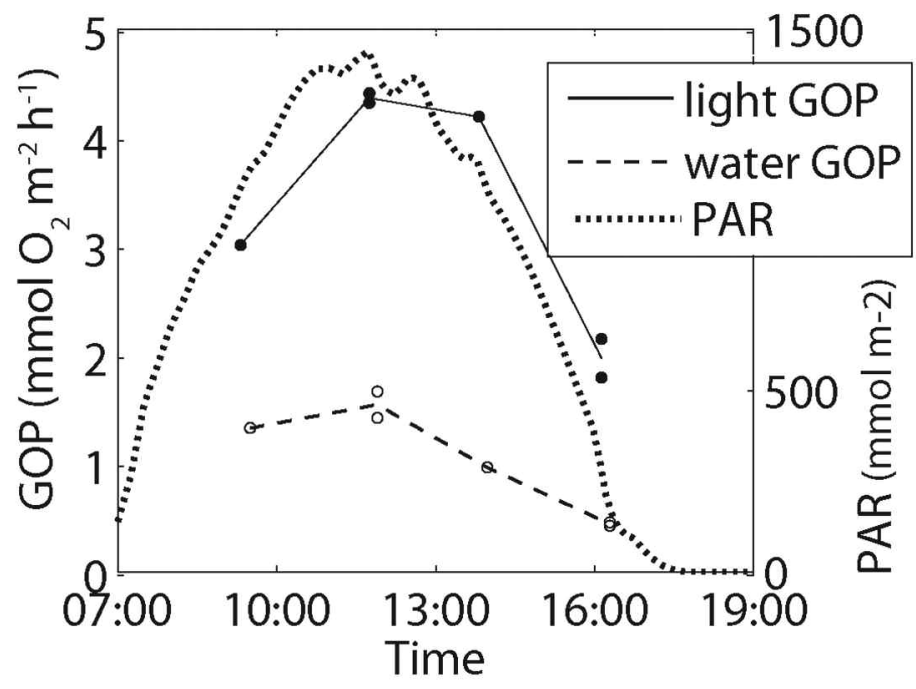

Fig. 4. Rates of GOP from the light and water chambers as well as PAR on 7 Oct 2011. The shapes of the GOP and PAR curves are similar.

Jahnke et al. 2008). Additionally, the shape of the GOP curves in the light and water chambers tracked the incoming photosynthetically active radiation (PAR), providing support that this method quantifies photosynthesis (Fig. 4).

Rates of GOP were slightly higher on 7 Oct than 10 Oct. Water quality data from the Metoxit Point in the middle of the bay collected by the Waquoit Bay National Estuarine Reserve (WBNER) shows that PAR was also higher on 7 Oct than on 10 Oct (Table 2). On short time-scales, we would expect PAR to be the controlling factor of GOP. Interestingly, chlorophyll concentrations in the water column were actually slightly lower on 7 Oct than 10 Oct, the reverse of GOP. Chl $a$ was not measured in the sediments. The disconnect between water column 
Table 2. Rates of GOP and environmental variables. Environmental data are averaged over the sampling period and calculated from chamber YSIs or from the Waquoit Bay National Esutarine Reserve data collection (http://cdmo.baruch.sc.edu/get/export.cfm\%5C).

\begin{tabular}{|c|c|c|c|c|c|c|c|c|c|}
\hline Chamber & $\begin{array}{c}\text { GOP } \\
\mathrm{mmol} \mathrm{O}_{2} \mathrm{~m}^{-2}\end{array}$ & $\begin{array}{l}\text { Time in } \\
\text { hh:mm }\end{array}$ & Time out & Dawn & Dusk & $\begin{array}{c}\text { Temp. } \\
{ }^{\circ} \mathrm{C}\end{array}$ & Sal. & $\begin{array}{r}\text { Chl } a \\
\mu g^{-1}\end{array}$ & $\begin{array}{c}\text { PAR } \\
\mathrm{mol} \mathrm{m}^{-2}\end{array}$ \\
\hline \multicolumn{10}{|l|}{7 Oct 2011} \\
\hline Light & $29.3 \pm 1.7$ & 7:55 & $17: 36$ & $6: 45$ & $18: 15$ & 17.4 & 30.2 & 3.9 & 35.55 \\
\hline Water & $9.5 \pm 0.7$ & $8: 06$ & $17: 47$ & $6: 45$ & $18: 15$ & 17.4 & 30.2 & 3.9 & 35.55 \\
\hline \multicolumn{10}{|c|}{10 Oct 2011} \\
\hline Light & $25.0 \pm 1.7$ & $7: 42$ & $17: 48$ & $6: 48$ & $18: 10$ & 19.2 & 30.2 & 4.6 & 34.76 \\
\hline Water & $7.3 \pm 0.7$ & $7: 58$ & $17: 56$ & $6: 48$ & $18: 10$ & 19.2 & 30.1 & 4.8 & 34.20 \\
\hline \multicolumn{10}{|c|}{15 Oct 2011} \\
\hline Light & $26.8 \pm 1.7$ & $7: 26$ & $17: 37$ & $6: 54$ & $18: 02$ & 17.2 & 29.2 & 2.9 & 31.91 \\
\hline Dark & $0.5 \pm 1.0$ & $7: 36$ & $17: 44$ & $6: 54$ & $18: 02$ & 17.2 & 29.2 & 2.9 & 31.91 \\
\hline
\end{tabular}

Chl $a$, and the water chamber GOP illustrates that biomass to productivity ratios can vary (as is well known) and exemplifies the need for direct measurements of rates of production.

We calculated the percentage of benthic and pelagic production by Eqs. 7 and 8 and found that MPB were responsible for approximately $67 \%$ to $71 \%$ of overall GOP (Table 1 ). This is a higher percentage than in Naragansett Bay where benthic GOP was $15 \%$ to $20 \%$ of total production even in the shallowest part of the bay and only 5\% in the deeper regions (Lake and Brush 2011) but is similar percentage to reports of up to $60 \%$ benthic contribution to overall GOP that have been observed in the South Atlantic Bight (Jahnke et al. 2000).

\section{Sampling frequency}

To assess how often one must sample from the chambers, we compared GOP rates calculated by integrating all the time points to GOP calculated by only using the initial and final TOI values (Table 1). The calculated rates of GOP in the light and water chambers were within $1 \sigma$ errors whether all time points were used or only the initial and final time points. Thus it is reasonable to only collect samples for TOI analyses at the beginning and end of the incubation, making sampling less time-intensive and easier to manage in places with poor accessibility. Additionally, initial and final sampling only would require less water to be drawn from the chamber and thus reduce any uncertainties or biases related to mixing of replacement water. In contrast, in the traditional light and dark method, one typically collects data at a minimum of 4 time points throughout the incubation.

\section{Uncertainty analysis}

We performed Monte Carlo analyses in order to calculate the uncertainty in the both the individually calculated GOP values at specific time points as well as the integrated total incubation GOP. To this end, we estimated the $1 \sigma$ uncertainty for each variable necessary for the calculation based on experimental or literature values (Table 3). We then assigned a value to each variable chosen randomly from a Gaussian distribution, where the mean of the distribution was the observed value and one standard deviation was equal to the assigned uncertainty. The calculations were solved ten thousand times with different randomly chosen variables to determine the standard error of the calculated GOP. When estimating daily rates, variables that are expected to co-vary between time points, such as the uncertainty in the value of the isotopic signature of the photosynthetic endmember, were assigned the same random value within each iteration for all time points.

To assess which factors caused the error in GOP, we performed a "knock-out" test where we assigned non-zero uncertainty to only one variable of interest at a time. We then performed ten thousand analyses with only that one variable varying for both the time point GOP (Table 4) and the integrated GOP (Table 5). This method provided the maximum potential error due to a particular source of uncertainty.

The overall uncertainty in the GOP estimates from a given chamber (light or water) is less than 10\%, whether the calculation is made using all the time points or the initial to final method only. The uncertainty in the benthic GOP, which is calculated as the difference between the light and water chambers (Eq. 6), is slightly larger because there is uncertainty from two chambers folded into the single number. Nonetheless, it is about $10 \%$, which is much smaller than error due to the assumption that the light respiration equals dark respiration, an assumption that is necessary for most other methods for quantifying gross primary production or GOP.

Measurement error of $\delta^{17} \mathrm{O}$ and $\delta^{18} \mathrm{O}$ contribute the largest fraction of overall error in calculated GOP (Tables 4 and 5). The measurement error was estimated as the difference between duplicate samples. It is almost double the uncertainty we measure from repeated equilibrated water samples prepared in the laboratory, probably because of difficulty in sampling the benthic flux chambers. The measurement error contributes a larger fraction at later time points (Table 4) because the rates of GOP are smaller later in the day whereas the absolute size of the measurement error does not change. Thus this TOI method will have the smallest uncertainties in regions with largest GOP rates. 
Table 3. Uncertainties for each variable used as inputs for Monte Carlo simulation to determine GOP rate uncertainties.

\begin{tabular}{lll}
\hline Variable & Uncertainty & Source \\
\hline$\delta^{17} \mathrm{O}_{\text {measured }}$ & $0.0320 \% \mathrm{o}$ & duplicates \\
$\delta^{18} \mathrm{O}_{\text {measured }}{ }^{*}{ }^{\times}$ & $0.0645 \% \mathrm{o}$ & duplicates \\
$\delta^{\times} \mathrm{O}_{\text {photoshynthesis }}$ & $0.14 \% 0$ & Eisenstadt et al. (2010) and Helman et al. (2005) \\
{$\left[\mathrm{O}_{2}\right]_{\text {chamber }}$} & $0.283 \mathrm{mg} \mathrm{L}^{-1}$ & YSI model 600xlm specifications \\
$\Delta \mathrm{t}$ & $2 \mathrm{~min}$ & sampling \\
$\gamma_{\mathrm{R}}$ & 0.0006 & Luz and Barkan (2005) \\
$V e x$ & $15 \mathrm{~mL}$ & sampling \\
Vtot & $160 \mathrm{~mL}$ & chamber height in sediment \\
\hline
\end{tabular}

*Based on adding in quadrature individual producer values

Table 4. Sources of error in the light chamber on 7 Oct 2011 at the time points listed in the top row. Standard errors (SE) are listed as the percentage of the calculated GOP for which the error could potentially account.

\begin{tabular}{lcccc}
\hline & \multicolumn{4}{c}{ Time } \\
\cline { 2 - 5 } SE (\% of GOP) & $\mathbf{9 : 1 9}$ & $\mathbf{1 1 : 4 5}$ & $\mathbf{1 3 : 4 9}$ & $\mathbf{1 6 : 0 8}$ \\
\hline Total & 7 & 7 & 11 & 15 \\
$\delta^{\times} \mathrm{O}_{\text {measured }}$ & 3 & 7 & 9 & 15 \\
$\delta^{\times} \mathrm{O}_{\text {photoshynthesis }}$ & 3 & 5 & 5 & 5 \\
{$\left[\mathrm{O}_{2}\right]_{\text {chamber }}$} & 2 & 2 & 1 & 2 \\
$\Delta \mathrm{t}$ & 1 & 2 & 2 & 1 \\
$\gamma_{\mathrm{R}}$ & 0 & 0 & 0 & 0 \\
$\mathrm{~V}_{\text {exchanged }}$ & 0 & 0 & 0 & 0 \\
$\mathrm{~V}_{\text {total }}$ & 0 & 0 & 0 & 0 \\
\hline
\end{tabular}

Table 5. Maximum potential error attributed to different sources based on Monte Carlo simulation. Uncertainty listed both as absolute standard error and as a percentage of the integrated benthic GOP on 7 Oct 2011.

\begin{tabular}{lcc}
\hline $\mathrm{GOP}\left(\mathrm{mmol} \mathrm{O} 2 \mathrm{~m}^{-2}\right)$ & 19.7 & \\
$\mathrm{SE}$ Total $\left(\mathrm{mmol} \mathrm{O}_{2} \mathrm{~m}^{-2}, \%\right.$ of GOP $)$ & 1.6 & $8 \%$ \\
\hline$\delta^{\times} \mathrm{O}_{\text {measured }}$ & 1.4 & $7 \%$ \\
$\delta^{\times} \mathrm{O}_{\text {photoshynthesis }}$ & 0.8 & $4 \%$ \\
{$\left[\mathrm{O}_{2}\right]_{\text {chamber }}$} & 0.3 & $2 \%$ \\
$\Delta \mathrm{t}$ & 0.3 & $2 \%$ \\
$\gamma_{\mathrm{R}}$ & 0 & $0 \%$ \\
Vex & 0 & $0 \%$ \\
Vtot & 0 & $0 \%$ \\
\hline
\end{tabular}

The second largest source of error stems from the uncertainty in the isotopic composition of oxygen produced by photosynthesis $\left(\delta^{x} O_{p}\right)$. The uncertainty attributed to that term was calculated assuming that the community composition at the site was known. Different types of phytoplankton (i.e., diatoms, cyanobacteria, etc.) have different isotopic signatures of oxygen produced in photosynthesis $\left(\delta^{x} O_{p}\right)$. The isotopic values can be determined to great precision (0.01\%) (Eisenstadt et al. 2010). However, in the limited amount of work done so far (Eisenstadt et al. 2010; Helman et al. 2005; Luz and Barkan 2011), it seems that different species within the same class, i.e., two different species of cyanobacteria, have isotopic values that differ by up to $0.1 \%$ and thus we used $0.1 \%$ added in quadrature for two MPB types $=0.14 \%$ o for the value assigned for the Monte Carlo simulation. However, if nothing is known about the community structure, a larger error must be assigned to $\delta^{\mathrm{x}} \mathrm{O}_{\mathrm{p}}$ than is listed in Table 3.

The calculations done in this work assumed that the community present was a 50\% mixture of diatoms and cyanobacteria based on two lines of evidence. First, at Childs River, a much more nutrient-rich site in the Waquoit Bay estuarine system, diatoms dominated whereas at Sage Lot Pond, a much less nutrient-rich site in the Waquoit Bay system, cyanobacteria dominated at times of year and in temperature ranges similar to those during our study period (Lever and Valiela 2005). Our site was in between those end-members in terms of nutrient loading and anthropogenic impact. Additionally, laboratory-based studies on community dependence on grain size and temperature (Watermann et al. 1999) found that for a grain size and temperature similar to what is present at Waquoit Bay, a mixture of cyanobacteria and diatoms should be present. For the 50/50 split that we assumed, a value of $29 \pm 2 \mathrm{mmol} \mathrm{O}_{2} \mathrm{~m}^{-2}$ is calculated for GOP in the light chamber on 7 Oct 2011. This GOP value could range from 25 to $35 \mathrm{mmol} \mathrm{O}_{2} \mathrm{~m}^{-2}$, depending on whether the community is completely cyanobacteria or completely diatoms. Thus to apply the TOI method with minimum error, one should determine the community composition (cyanobacteria, diatoms, etc.) at the time of sampling so one can accurately constrain $\delta^{\mathrm{x}} \mathrm{O}_{\mathrm{p}}$. Additionally, more work should be done to determine whether the isotopic values are different for different species of diatoms or cyanobacteria and if pelagic species are different than benthic ones.

Uncertainty from the concentration of $\mathrm{O}_{2}$, measured by a model 600xlmYSI calibrated to saturation in air, contributed roughly $2 \%$ of the overall uncertainty in GOP rates. Uncertainties from other sources such as the estimate of the volume of water replaced during sampling, respiration factor $\gamma_{R^{\prime}}$ temperature, and exact time samples were taken, were all negligible. 
Confirmation that respiration does not change the TOI signature ${ }^{17} \Delta$

To confirm that the premise behind this method is sound, we analyzed TOI in samples collected from a dark chamber. We hypothesized that the ${ }^{17} \Delta$ of the dark chamber would not change over the course of the day and that GOP calculated from the $\delta^{17} \mathrm{O}$ and $\delta^{18} \mathrm{O}$ values (Eq. 3-5) would be within errors of zero because the TOI signature is not sensitive to respiration. Insofar that other oxygen consumption reactions (e.g., Mackin and Swider 1989) within the sediment are all massdependent, it should not be sensitive to those reactions either. However, other oxygen consumption reactions may have slightly different slopes than 0.5179 so there could be some sensitivity to those reactions.

On 15 Oct 2011, we deployed a light chamber and a dark chamber in Waquoit Bay, near where we had deployed the light and water column chambers the previous days. The dark chamber was of similar design to the light one, except that the top was black, and we put a neoprene casing around the sides to prevent any light from getting into the chamber. The ${ }^{17} \Delta$ increased in the light chamber, as expected, due to photosynthesis from MPB and from phytoplankton in the overlying water (Fig. 5a). In the dark chamber, the ${ }^{17} \Delta$ stayed constant, within measurement errors, confirming that ${ }^{17} \Delta$ in the flux chambers is not sensitive to respiration. We calculated GOP from the chambers according to Eq. 3-5 and found that whereas there was significant GOP in the light chamber, GOP was within errors of zero in the dark chamber (Fig. 5b). The oxygen content of the dark chamber, as measured by the YSI, decreased, indicating respiration in the dark chamber. Thus we confirmed that TOI measured in the flux chambers are not sensitive to respiration, and hence, that TOI can quantify GOP without any assumptions necessary about respiration.

\section{Comparison to light/dark method}

Unfortunately, we do not have a "gold standard" to compare these GOP numbers to; the motivation for this method is that there are no good current methods for measuring MBP gross primary production or GOP. Although it is interesting to compare the rates of GOP calculated from TOI to GOP estimated from dissolved oxygen (DO) concentrations from light and dark chambers, such a comparison is not definitive since differences in light and dark respiration would make the GOP calculated from the two methods differ. Additionally, to properly do the comparison, one would need to deploy at least 3 pairs of light and dark chambers because of inherent spatial heterogeneity in MPB communities; such a study was outside the scope of the method development work presented here. Nonetheless, here we compare the GOP calculated from the TOI method in the light chamber and GOP calculated from the DO fluxes in light and dark chambers. GOP calculated from the two methods agrees surprisingly well. From the TOI method in the light chamber, the GOP was $27 \pm 2 \mathrm{mmol} \mathrm{O}_{2} \mathrm{~m}^{-2}$ whereas using the light-dark method, the GOP was $32 \pm 10 \mathrm{mmol} \mathrm{O}_{2} \mathrm{~m}^{-2}$. Both methods show the same diurnal pattern of GOP (Fig. 6).
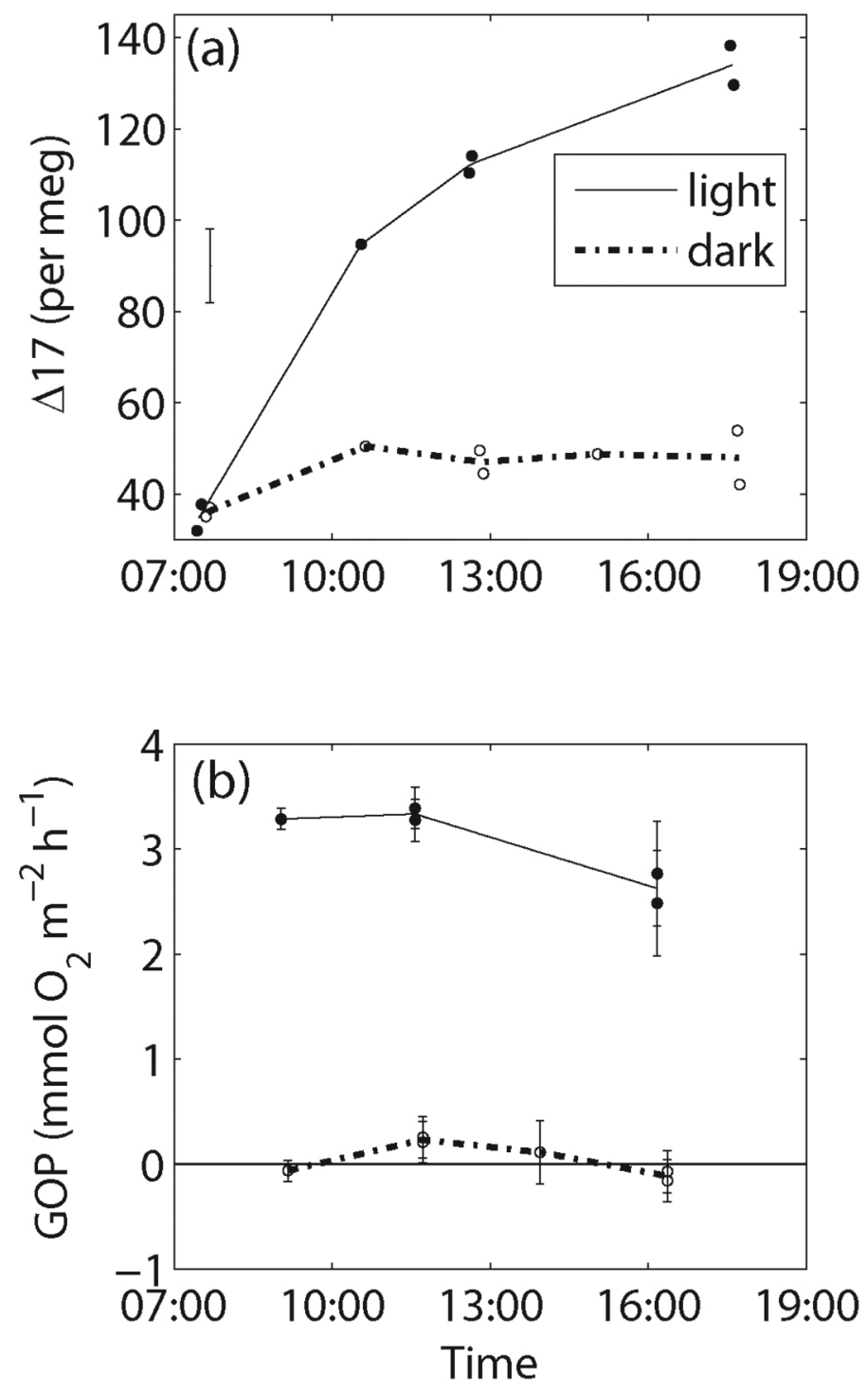

Fig. 5. (a) The triple isotopic signature, ${ }^{17} \Delta$, in the light and dark chambers on 15 Oct 2011. The error bar in top left corner reflects $1 \sigma$ measurement uncertainty. Triple oxygen isotopes (TOI) are not sensitive to respiration and thus ${ }^{17} \Delta$ in the dark chamber does not change throughout the course of the incubation. (b) Rates of GOP in the two chambers. Error bars on all GOP rates represent $1 \sigma$ uncertainty from Monte Carlo analysis. The rate of GOP in the dark chambers is within error of zero, confirming that the TOI method is not influenced by respiration.

\section{Comparison to ${ }^{18} \mathrm{O}$ incubation technique}

In theory, one could spike water in a benthic flux chamber with ${ }^{18} \mathrm{O}$ labeled $\mathrm{H}_{2} \mathrm{O}$ and use the evolution of ${ }^{18} \mathrm{O}$ labeled $\mathrm{O}_{2}$ to quantify GOP, in a fashion similar to what is done in bottle incubation experiments on seawater from the open ocean (Bender et al. 1987). In this so-called ${ }^{18} \mathrm{O}$ incubation technique, the concentration of ${ }^{18} \mathrm{O}$ label in the seawater is so much greater than the biomass that recycling of labeled $\mathrm{O}_{2}$ is very small and thus the results are insensitive to uncertainties in isotopic respiration factor. This technique has not been applied in 


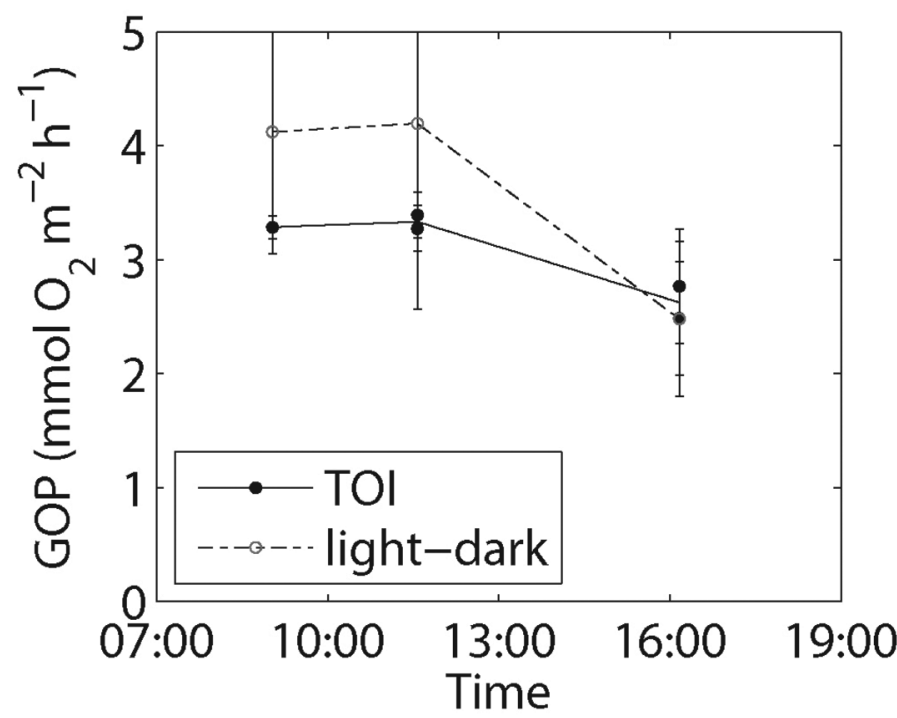

Fig. 6. Rates of GOP calculated from the light chamber on 15 Oct 2011 using the triple oxygen isotope method and the traditional light-dark dissolved oxygen method. The two methods agree well (within 1 $\sigma$ errors) despite the different assumptions of the techniques and unaccounted for spatial heterogeneity. Note the final light-dark point overlaps one of the final TOI points.

benthic flux chambers to quantify MPB photosynthesis but could be done and thus could serve as a standard for comparison with other measurements of MPB photosynthetic rates.

There are several advantages and disadvantages of the ${ }^{18} \mathrm{O}$ labeled approach compared with the TOI approach presented here. The main advantage of the ${ }^{18} \mathrm{O}$ incubations are that the enrichments in ${ }^{18} \mathrm{O}$ are large and thus are much easier to measure than the natural variations in TOI. For example, measurement uncertainty is typically less than $2 \%$ for ${ }^{18} \mathrm{O}$ incubations (Bender et al. 1999) whereas it results in about an 5\% error for TOI approach and also more laboratories are capable of measuring variations in spiked ${ }^{18} \mathrm{O}$ than natural variations in TOI. A second advantage for the ${ }^{18} \mathrm{O}$ incubation approach is that although uncertainties in the fractionation associated with photosynthesis will affect both the ${ }^{18} \mathrm{O}$ incubation approach and the TOI approach, the fractionation has a much smaller effect on the ${ }^{18} \mathrm{O}$ incubation since the spiked water is so enriched in ${ }^{18} \mathrm{O}$.

One disadvantage of the ${ }^{18} \mathrm{O}$ incubation is that it involves artificially spiking the water with an isotope in situ. Given that MPB photosynthesis often occurs in coastally sensitive regions, obtaining permission to spike the water from local watershed managers might be difficult, even though ${ }^{18} \mathrm{O}$ in itself is harmless. In the open ocean, there is not this problem since the ${ }^{18} \mathrm{O}$ incubations are done either onboard the ship or in confined bottles so that the tracer never escapes into the environment. Additionally, the correction for volume of water replaced during sampling would be more important for ${ }^{18} \mathrm{O}$ incubation approach than the TOI one since the incoming water would have a very different isotopic composition from the artificially spiked water in the chamber. Thus any uncertainties in the volume of the incoming water would be more important. Similarly, if groundwater is entering the chamber during the experiment, the difference in isotopic composition between the groundwater and chamber water will be more extreme for the ${ }^{18} \mathrm{O}$ approach than the TOI approach and thus likely to cause a larger error.

Both the ${ }^{18} \mathrm{O}$ approach and the TOI approach have the advantages of being insensitive to respiration so clearly quantify GOP.

\section{Discussion}

The TOI method for quantifying microphytobenthic gross primary production that is presented in this article is a fundamentally new method for quantifying benthic photosynthesis. In an example application, the overall uncertainty in the MPB GOP rates was approximately $10 \%$. The TOI method avoids many of the shortcomings of the standard techniques. Perhaps most importantly, it does not require any assumptions about light respiration equaling dark respiration. Because samples are taken from an in situ benthic flux chambers, as opposed to a core removed to a laboratory, relatively little disturbance to the benthic community occurs and the community is exposed to ambient light and temperature that is difficult to reproduce in a laboratory setting. Because samples only need to be taken at the start and end of the incubation (rather than at multiple time points within the incubation), sampling is logistically easier than with some other approaches. This fundamentally new TOI approach will allow quantitative investigation of benthic photosynthesis, an important part of the estuarine carbon cycle that is often not quantified.

The TOI method does have limitations. First, the samples are taken from a benthic flux chamber, and thus, there are issues of enclosures altering the turbulence, which might affect production, of advection through the sediments, of grazer exclusion, and of spatial heterogeneity in the microalgal communities. The first two issues can be addressed by choosing appropriate field sites and the final issue by deploying multiple flux chambers at once. Second, TOI samples are difficult to measure, requiring a specialized processing line and an isotope ratio mass spectrometer. Therefore, rather than being used routinely, the TOI method will likely be used in targeted locations where process-based studies are used to extend the knowledge learned from TOI-derived GOP to more general circumstances. For example, the TOI method could be used to learn about the factors controlling biomass-productivity ratios, light versus dark respiration in different environments, or the quantitative response of MPB photosynthesis to anthropogenic impact such as eutrophication.

\section{Comments and recommendations}

Culturing experiments should be performed to measure the isotopic values of oxygen produced by photosynthesis 
for MPB. The values used in the example application presented here are for pelagic species, and it is unknown whether benthic species would have the same fractionation. Additionally, more tests should be done to confirm that oxygen consumption reactions within the sediment do not affect the TOI signature. Such reactions could have different relative fractionation between ${ }^{17} \mathrm{O}$ and ${ }^{18} \mathrm{O}$ than does respiration (i.e., a $\gamma$ different than 0.5179). In the future, the oxygen concentration in the chamber could be determined more precisely by Winkler titration than by the YSI used in this study, decreasing the uncertainty in the method. Finally, this method should not be applied in areas where there are large groundwater fluxes into the benthic flux chambers unless the groundwater end-member TOI signature can be measured and the flux of groundwater estimated.

The same measurements that yield the TOI signature of the samples also provide the $\mathrm{O}_{2} / \mathrm{Ar}$ ratio in the sample (Barkan and Luz 2003). Ar has a similar solubility and molecular diffusivity to $\mathrm{O}_{2}$ and thus can serve as an abiotic analogue of $\mathrm{O}_{2}$. In the open ocean, $\mathrm{O}_{2} / \mathrm{Ar}$ ratios are used to quantify net community production (e.g., Craig and Hayward 1987; Spitzer and Jenkins 1989). In theory, the same approach could be taken here to quantify net community production (NCP) in the benthic flux chambers. However, since the isotope ratio mass spectrometer yields the ratio of $\mathrm{O}_{2}$ to $\mathrm{Ar}$ (rather than the absolute values), NCP can only be calculated by either combining the $\mathrm{O}_{2} / \mathrm{Ar}$ ratios with the YSI $\mathrm{O}_{2}$ concentration at the initial time point or by assuming that the initial Ar saturation is $100 \%$. The assumption about Ar saturation, whereas often satisfactory in the open ocean, may not be good for the flux chambers. If one does the former, then one can calculate NCP rates and compare them to NCP rates calculated directly from the YSI; for example in the application discussed above the $\mathrm{O}_{2} / \mathrm{Ar}$ derived NCP for the light chamber is $18.3 \mathrm{mmol} \mathrm{O}_{2} \mathrm{~m}^{-2}$ whereas the $\mathrm{YSI} \mathrm{O}_{2}$ NCP for the light chamber is $18.5 \mathrm{mmol} \mathrm{O}_{2} \mathrm{~m}^{-2}$ on 15 Oct 2011. However, on 7 Oct 2011 and 10 Oct 2011, the two methods disagree: NCP in the light chamber is $22 \mathrm{mmol} \mathrm{O}_{2}$ $\mathrm{m}^{-2}$ from $\mathrm{O}_{2} / \mathrm{Ar}$ and $13.7 \mathrm{mmol} \mathrm{O}_{2} \mathrm{~m}^{-2}$ from the YSI method on the former and is $23 \mathrm{mmol} \mathrm{O}_{2} \mathrm{~m}^{-2}$ from $\mathrm{O}_{2} / \mathrm{Ar}$ and 14.5 $\mathrm{mmol} \mathrm{O}_{2} \mathrm{~m}^{-2}$ from the YSI method on the latter, all numbers reported for the light chamber. The advantage of the $\mathrm{O}_{2} / \mathrm{Ar}$ method is that drift in the YSI measurements throughout the day does not matter. The disadvantage is that it is much more difficult unless one is measuring TOI anyway and that one has to assume an initial Ar value. These values of NCP, which are approximately 50\% to $75 \%$ of the GOP values reported for the light chamber on those days, are relatively high but within a reasonable range for a high productivity environments. The NCP calculations described here could be done for the water chamber as well and then the difference between the two chambers could be used to determine MPB net community production rates.

\section{References}

Angert, A., S. Rachmilevitch, E. Barkan, and B. Luz. 2003. Effects of photorespiration, the cytochrome pathway, and the alternative pathway on the triple isotopic composition of atmospheric O-2. Global Biogeochem. Cycles 17.

Barkan, E., and B. Luz. 2003. High-precision measurements of O-17/O-16 and O-18/O-16 of O-2 and O-2/Ar ratio in air. Rapid Comm. Mass Spectrom. 17:2809-2814 [doi:10.1002/ rcm.1267].

Bender, M., and others. 1987. A comparison of 4 methods for determining planktonic community production. Limnol. Oceanogr. 32:1085-1098 [doi:10.4319/1o.1987.32.5.1085].

—, J. Orchardo, M. L. Dickson, R. Barber, and S. Lindley. 1999. In vitro O-2 fluxes compared with C-14 production and other rate terms during the JGOFS Equatorial Pacific experiment. Deep-Sea Res. I 46:637-654 [doi:10.1016/S09670637(98)00080-6].

Berg, P., H. Roy, F. Janssen, V. Meyer, B. B. Jorgensen, M. Huettel, and D. de Beer. 2003. Oxygen uptake by aquatic sediments measured with a novel non-invasive eddy-correlation technique. Mar. Ecol. Progr. Ser. 261:75-83 [doi:10. 3354/meps261075].

Borges, A. V., B. Delille, and M. Frankignoulle. 2005. Budgeting sinks and sources of $\mathrm{CO} 2$ in the coastal ocean: Diversity of ecosystems counts. Geophys. Res. Lett. 32 [doi:10. 1029/2005GL023053].

Bricker, S., B. Longstaff, W. Dennison, A. Jones, K. Boicourt, C. Wicks, and J. Woerner. 2007. Effects of nutrient enrichment in the nation's estuaries: a decade of change. In Effects of nutrient enrichment in the nation's estuaries: a decade of change, NOAA Coastal Ocean Program Decision Analysis Series, 328. National Centers for Coastal Ocean Science.

Cai, W. J. 2011. Estuarine and Coastal Ocean Carbon Paradox: $\mathrm{CO}(2)$ sinks or sites of terrestrial carbon incineration?, p. 123-145. In C. A. Carlson and S. J. Giovannoni [eds.], Annual review of marine science, Vol 3. Annual Reviews.

-, M. H. Dai, and Y. C. Wang. 2006. Air-sea exchange of carbon dioxide in ocean margins: A province-based synthesis. Geophys. Res. Lett. 33 [doi:10.1029/2006GL026219].

Cebrian, J., and others. 2008. The impact of Hurricane Ivan on the primary productivity and metabolism of marsh tidal creeks in the North Central Gulf of Mexico. Aquat. Ecol. 42:391-404 [doi:10.1007/s10452-007-9096-0].

Charette, M. A., K. O. Buesseler, and J. E. Andrews. 2001. Utility of radium isotopes for evaluating the input and transport of groundwater-derived nitrogen to a Cape Cod estuary. Limnol. Oceanogr. 46:465-470 [doi:10.4319/lo.2001. 46.2.0465].

Chen, C. T. A., and A. V. Borges. 2009. Reconciling opposing views on carbon cycling in the coastal ocean: Continental shelves as sinks and near-shore ecosystems as sources of atmospheric CO2. Deep-Sea Res. II 56:578-590 [doi:10. 1016/j.dsr2.2009.01.001]. 
Cibic, T., O. Blasutto, N. Burba, and S. F. Umani. 2008. Microphytobenthic primary production as C-14 Uptake in sublittoral sediments of the Gulf of Trieste (northern Adriatic Sea): Methodological aspects and data analyses. Estuar. Coast. Shelf Sci. 77:113-122 [doi:10.1016/j.ecss.2007. 09.005].

Cloern, J. E. 2001. Our evolving conceptual model of the coastal eutrophication problem. Mar. Ecol. Progr. Ser. 210:223-253 [doi:10.3354/meps210223].

- C. Grenz, and L. VidergarLucas. 1995. An empirical model of the phytoplankton chlorophyll:carbon ratio-The conversion factor between productivity and growth rate. Limnol. Oceanogr. 40:1313-1321.

Cook, P. L. M., B. Veuger, S. Boer, and J. J. Middelburg. 2007. Effect of nutrient availability on carbon and nitrogen incorporation and flows through benthic algae and bacteria in near-shore sandy sediment. Aquat. Microb. Ecol. 49:165180 [doi:10.3354/ame01142].

Craig, H., and T. Hayward. 1987. Oxygen supersaturation in the ocean: biological versus physical contributions. Science 235:199-202 [doi:10.1126/science.235.4785.199].

de Jonge, V. N., M. Elliott, and E. Orive. 2002. Causes, historical development, effects and future challenges of a common environmental problem: eutrophication. Hydrobiologia 475:1-19 [doi:10.1023/A:1020366418295].

Diaz, R. J. 2001. Overview of hypoxia around the world. J. Environ. Qual. 30:275-281 [doi:10.2134/jeq2001.302275x].

_, and R. Rosenberg. 1995. Marine benthic hypoxia: A review of its ecological effects and the behavioural responses of benthic macrofauna, p. 245-303. In Oceanography and marine biology: an annual review, Vol 33. U C L Press Ltd.

Dring, M. J., and D. H. Jewson. 1982. What does C-14 uptake by phytoplankton really measure? A theoretical modeling approach. Proc. R. Soc. Lond. Ser. B 214:351-368 [doi:10. 1098/rspb.1982.0016].

Eisenstadt, D., E. Barkan, B. Luz, and A. Kaplan. 2010. Enrichment of oxygen heavy isotopes during photosynthesis in phytoplankton. Photosynth. Res. 103:97-103 [doi:10.1007/ s11120-009-9518-z].

Emerson, S., C. Stump, D. Wilbur, and P. Quay. 1999. Accurate measurement of $\mathrm{O}-2, \mathrm{~N}-2$, and Ar gases in water and the solubility of N-2. Mar. Chem. 64:337-347 [doi:10.1016/ S0304-4203(98)00090-5].

Engelsen, A., S. Hulth, L. Pihl, and K. Sundback. 2008. Benthic trophic status and nutrient fluxes in shallow-water sediments. Estuar. Coast. Shelf Sci. 78:783-795 [doi:10.1016/ j.ecss.2008.02.018].

Epping, E. H. G., and B. B. Jorgensen. 1996. Light-enhanced oxygen respiration in benthic phototrophic communities. Mar. Ecol. Progr. Ser. 139:193-203 [doi:10.3354/meps 139193].

Eyre, B. D., and A. J. P. Ferguson. 2002. Comparison of carbon production and decomposition, benthic nutrient fluxes and denitrification in seagrass, phytoplankton, benthic microalgae- and macroalgae-dominated warm-temperate Australian lagoons. Mar. Ecol. Progr. Ser. 229:43-59 [doi:10.3354/meps229043].

- and 2 2005. Benthic metabolism and nitrogen cycling in a subtropical east Australian Estuary (Brunswick): Temporal variability and controlling factors. Limnol. Oceanogr. 50:81-96 [doi:10.4319/lo.2005.50.1.0081].

Fenchel, T., and R. N. Glud. 2000. Benthic primary production and O-2-CO2 dynamics in a shallow-water sediment: Spatial and temporal heterogeneity. Ophelia 53:159-171.

Flynn, K. J. 2003. Do we need complex mechanistic photoacclimation models for phytoplankton? Limnol. Oceanogr. 48:2243-2249 [doi:10.4319/lo.2003.48.6.2243].

Glud, R. N., P. Berg, A. Hume, P. Batty, M. E. Blicher, K. Lennert, and S. Rysgaard. 2010. Benthic $\mathrm{O}(2)$ exchange across hard-bottom substrates quantified by eddy correlation in a sub-Arctic fjord. Mar. Ecol. Progr. Ser. 417:1-12 [doi:10.3354/meps08795].

Halsey, K. H., A. J. Milligan, and M. J. Behrenfeld. 2010. Physiological optimization underlies growth rate-independent chlorophyll-specific gross and net primary production. Photosynth. Res. 103:125-137 [doi:10.1007/s11120-0099526-z].

Hamme, R. C., and S. Emerson. 2004. Measurement of dissolved neon by isotope dilution using a quadrupole mass spectrometer. Mar. Chem. 91:53-64 [doi:10.1016/j.mar chem.2004.05.001].

Helman, Y., E. Barkan, D. Eisenstadt, B. Luz, and A. Kaplan. 2005. Fractionation of the three stable oxygen isotopes by oxygen-producing and oxygen-consuming reactions in photosynthetic organisms. Plant Physiol. 138:2292-2298 [doi:10.1104/pp.105.063768].

Hendricks, M. B., M. L. Bender, and B. A. Barnett. 2004. Net and gross $\mathrm{O}-2$ production in the Southern Ocean from measurements of biological O-2 saturation and its triple isotope composition. Deep-Sea Res. I 51:1541-1561.

, M. L. Bender, B. A. Barnett, P. Strutton, and F. P. Chavez. 2005. Triple oxygen isotope composition of dissolved O-2 in the equatorial Pacific: A tracer of mixing, production, and respiration. J. Geophys. Res. Oceans 110 [doi:10.1029/2004JC002735].

Hopkinson, C., A. Giblin, J. Tucker, and R. Garritt. 1999. Benthic metabolism and nutrient cycling along an estuarine salinity gradient. Estuar. Coasts 22:863-881 [doi:10.2307/ 1353067].

Hopkinson, C. S., and E. M. Smith. 2005. Estuarine respiration: an overview of benthic, pelagic, and whole system respiration. In P. A. del Giorgio and P. J. B. Williams [eds.], Respiration in aquatic ecosystems. Oxford Univ. Press [doi:10.1093/acprof:oso/9780198527084.003.0008].

Jahnke, R. A., J. R. Nelson, R. L. Marinelli, and J. E. Eckman 2000. Benthic flux of biogenic elements on the Southeastern US continental shelf: influence of pore water advective 
transport and benthic microalgae. Cont. Shelf Res. 20:109127 [doi:10.1016/S0278-4343(99)00063-1].

—, J. R. Nelson, M. E. Richards, C. Y. Robertson, A. M. F. Rao, and D. B. Jahnke. 2008. Benthic primary productivity on the Georgia midcontinental shelf: Benthic flux measurements and high-resolution, continuous in situ PAR records. J. Geophys. Res. Oceans 113: C08022.

Kaiser, J. 2011. Technical note: Consistent calculation of aquatic gross production from oxygen triple isotope measurements. Biogeosciences 8:1793-1811 [doi:10.5194/bg-81793-2011].

Kemp, W. M., J. M. Testa, D. J. Conley, D. Gilbert, and J. D. Hagy. 2009. Temporal responses of coastal hypoxia to nutrient loading and physical controls. Biogeosciences 6:29853008 [doi:10.5194/bg-6-2985-2009].

Lake, S. J., and M. J. Brush. 2011. The contribution of microphytobenthos to total productivity in upper Narragansett Bay, Rhode Island. Estuar. Coast. Shelf Sci. 95:289-297 [doi:10.1016/j.ecss.2011.09.005].

Lammerzahl, P., T. Rockmann, C. A. M. Brenninkmeijer, D. Krankowsky, and K. Mauersberger. 2002. Oxygen isotope composition of stratospheric carbon dioxide. Geophys. Res. Lett [doi:10.1029/2001GL014343].

Laws, E. A., M. R. Landry, R. T. Barber, L. Campbell, M. L. Dickson, and J. Marra. 2000. Carbon cycling in primary production bottle incubations: inferences from grazing experiments and photosynthetic studies using C-14 and O-18 in the Arabian Sea. Deep-Sea Res. II 47:1339-1352 [doi:10.1016/S0967-0645(99)00146-0].

Lever, M. A., and I. Valiela. 2005. Response of microphytobenthic biomass to experimental nutrient enrichment and grazer exclusion at different land-derived nitrogen loads. Mar. Ecol. Progr. Ser. 294:117-129 [doi:10.3354/meps 294117].

Lorrai, C., D. F. McGinnis, P. Berg, A. Brand, and A. Wuest. 2010. Application of oxygen eddy correlation in aquatic systems. J. Atmos. Ocean. Technol. 27:1533-1546 [doi:10. 1175/2010JTECHO723.1].

Lott, D. E. 2001. Improvements in noble gas separation methodology: a nude cryogenic trap. Geochem. Geophys. Geosys. 2:10.129/2001GC000202.

Luz, B., E. Barkan, M. L. Bender, M. H. Thiemens, and K. A. Boering. 1999. Triple-isotope composition of atmospheric oxygen as a tracer of biosphere productivity. Nature 400:547-550 [doi:10.1038/22987].

- and E. Barkan. 2000. Assessment of oceanic productivity with the triple-isotope composition of dissolved oxygen. Science 288:2028-2031 [doi:10.1126/science.288.5473. 2028].

- and 2005. The isotopic ratios $0-17 / \mathrm{O}-16$ and O-18/O-16 in molecular oxygen and their significance in biogeochemistry. Geochim. Cosmochim. Acta 69:10991110 [doi:10.1016/j.gca.2004.09.001].

— from O-2/Ar, O-17/O-16 and O-18/O-16 ratios. Aquat. Microb. Ecol. 56:133-145 [doi:10.3354/ame01296].

, and - 2011. Proper estimation of marine gross $\mathrm{O}(2)$ production with $(17) \mathrm{O} /(16) \mathrm{O}$ and $(18) \mathrm{O} /(16) \mathrm{O}$ ratios of dissolved O(2). Geophys. Res. Lett. 38:L19606.

MacIntyre, H. L., R. J. Geider, and D. C. Miller. 1996. Microphytobenthos: The ecological role of the "secret garden" of unvegetated, shallow-water marine habitats. 1. Distribution, abundance and primary production. Estuaries 19:186201 [doi:10.2307/1352224].

Mackin, J. E., and K. T. Swider. 1989. Organic matter decomposition pathways and oxygen-consumption in coastal marine sediments. J. Mar. Res. 47:681-716 [doi:10.1357/002224089785076154].

McGinnis, D. F., P. Berg, A. Brand, C. Lorrai, T. J. Edmonds, and A. Wuest. 2008. Measurements of eddy correlation oxygen fluxes in shallow freshwaters: Towards routine applications and analysis. Geophys. Res. Lett. 35.

McGlathery, K. J., I. C. Anderson, and A. C. Tyler. 2001. Magnitude and variability of benthic and pelagic metabolism in a temperate coastal lagoon. Mar. Ecol. Progr. Ser. 216:1-15 [doi:10.3354/meps216001].

—, K Sundback, and I. C. Anderson. 2004. The importance of primary producers for benthic nitrogen and phosphorus cycling, p. 231-261. In S. L Nielsen, G. T. Banta, and M. F. PedersonDordrecht [eds.], Estuarine nutrient cycling: The influence of primary producers. Kluwer Academic Publishers [doi:10.1007/978-1-4020-3021-5_9].

Meyercordt, J., and L. A. Meyer-Reil. 1999. Primary production of benthic microalgae in two shallow coastal lagoons of different trophic status in the southern Baltic Sea. Mar. Ecol. Progr. Ser. 178:179-191 [doi:10.3354/meps178179].

Nixon, S. W. 1995. Coastal marine eutrophication-a definition, social causes, and future concerns. Ophelia 41:199-219.

Paerl, H. W. 1988. Nuisance phytoplankton blooms in coastal, estuarine, and inland waters. Limnol. Oceanogr. 33:823847 [doi:10.4319/lo.1988.33.4_part_2.0823].

Prokopenko, M. G., O. M. Pauluis, J. Granger, and L. Y. Yeung. 2011. Exact evaluation of gross photosynthetic production from the oxygen triple-isotope composition of $\mathrm{O}(2)$ : Implications for the net-to-gross primary production ratios. Geophys. Res. Lett. 38.

Rabalais, N. N., W. J. Wiseman, R. E. Turner, B. K. SenGupta, and Q. Dortch. 1996. Nutrient changes in the Mississippi River and system responses on the adjacent continental shelf. Estuaries 19:386-407 [doi:10.2307/1352458].

Rao, A. M., and M. Charette. 2011. Benthic nitrogen fixation in an eutrophic estuary affected by groundwater discharge. J. Coast. Res. 28:477-485.

Reuer, M. K., B. A. Barnett, M. L. Bender, P. G. Falkowski, and M. B. Hendricks. 2007. New estimates of Southern Ocean biological production rates from O-2/Ar ratios and the triple isotope composition of O-2. Deep-Sea Res. I 54:951974 [doi:10.1016/j.dsr.2007.02.007]. 
Risgaard-Petersen, N. 2003. Coupled nitrification-denitrification in autotrophic and heterotrophic estuarine sediments: On the influence of benthic microalgae. Limnol. Oceanogr. 48:93-105 [doi:10.4319/lo.2003.48.1.0093].

Rysgaard, S., P. B. Christensen, and L. P. Nielsen. 1995. Seasonal-variation in nitrification and denitrification in estuarine sediment colonized by benthic microlagae and bioturtbating infauna. Mar. Ecol. Progr. Ser. 126:111-121 [doi:10.3354/meps126111].

Spitzer, W. S., and W. J. Jenkins. 1989. Rates of vertical mixing, gas-exchange and new production - estimates from seasonal gas cycles in the upper ocean near Bermuda. J. Mar. Res. 47:169-196 [doi:10.1357/002224089785076370].

Stanley, R. H. R., J. B. Kirkpatrick, B. Barnett, N. Cassar, and M. L. Bender. 2010. Net community production and gross production rates in the Western Equatorial Pacific. Global Biogeochem. Cycles 24:GB4001.

Sundbäck, K., V. Enoksson, W Graneli, and K. Pettersson. 1991. Influence of sublittoral microphytobenthos on the oxygen and nutrient flux between sediment and water: a laboratory continuous-flow study. Mar. Ecol. Progr. Ser. 74:263-279.

Thiemens, M. H., T. Jackson, E. C. Zipf, P. W. Erdman, and C. Vanegmond. 1995. Carbon-dioxide and oxygen-isotope anomalies in the mesosphere and stratosphere. Science 270:969-972 [doi:10.1126/science.270.5238.969].

Thronson, A., and A. Quigg. 2008. Fifty-five years of fish kills in coastal Texas. Estuar. Coasts 31:802-813 [doi:10.1007/ s12237-008-9056-5].
Turner, R. E., and N. N. Rabalais. 1994. Coastal eutrophiciation near the Mississippi river delta Nature 368:619-621 [doi:10.1038/368619a0].

Tyler, A. C., K. J. McGlathery, and I. C. Anderson. 2003. Benthic algae control sediment-water column fluxes of organic and inorganic nitrogen compounds in a temperate lagoon. Limnol. Oceanogr. 48:2125-2137 [doi:10.4319/lo.2003.48. 6.2125].

Underwood, G. J. C., and J. Kromkamp. 1999. Primary production by phytoplankton and microphytobenthos in estuaries, p. 93-153. In Advances in ecological research, Vol 29. Academic Press [doi:10.1016/S0065-2504(08)60192-0].

Valiela, I., J. Costa, K. Foreman, J. M. Teal, B. Howes, and D. Aubrey. 1990. Transport of groundwater-borne nutrients from watersheds and their effects on coastal waters. Biogeochemistry 10:177-197 [doi:10.1007/BF00003143].

Vaquer-Sunyer, R., and C. M. Duarte. 2008. Thresholds of hypoxia for marine biodiversity. Proc. Nat. Acad. Sci. U.S.A.105:15452-15457 [doi:10.1073/pnas.0803833105].

Watermann, F., H. Hillebrand, G. Gerdes, W. E. Krumbein, and U. Sommer. 1999. Competition between benthic cyanobacteria and diatoms as influenced by different grain sizes and temperatures. Mar. Ecol. Progr. Ser. 187:77-87 [doi:10.3354/ meps187077].

Submitted 12 September 2012 Accepted 15 October 2012 